\title{
Original
}

\section{Resting energy expenditure in short-stature children}

\author{
Yukiko Nishimoto $^{1), 2)}$, Shinobu Ida $^{3)}$, Yuri Etani ${ }^{3)}$ and Shuichi Miyatani ${ }^{2)}$ \\ 1) Department of Nutrition, Osaka Medical Center and Research Institute for Maternal and Child Health, Izumi 594-1101, Japan \\ 2) Graduate School of Comprehensive Rehabilitation, Osaka Prefecture University, Habikino 583-8555, Japan \\ 3) Division of Pediatric Gastroenterology, Nutrition and Endocrinology, Osaka Medical Center and Research Institute for \\ Maternal and Child Health, Izumi 594-1101, Japan
}

\begin{abstract}
It is not clear what dietary intake standards should be used for children with abnormal body size. To investigate the energy requirements of short-stature children with no underlying diseases, their resting energy expenditure (REE) were measured by indirect calorimetry. The short-stature group consisted of 30 prepubertal children with short stature and with no underlying diseases (age $6 \mathrm{y} \pm 2$ ) and the control group consisted of 13 age-matched children with standard stature. Fasting REE and the respiration quotient (RQ) with subjects in the supine position were measured by canopy indirect calorimetry. Actual measurements and body-size-adjusted REEs were compared between the groups. Also, REE measurements were compared with the basal metabolic rate (BMR) calculated using the Dietary Reference Intakes for Japanese (Dietary Reference Intakes). REE in the control group was significantly higher than that in the short-stature group. However, body-size-adjusted REEs were significantly higher for the short-stature group. When the actual REE was compared with the calculated BMR within both the control group and the short-stature group, which was acquired using the Dietary Reference Intakes, there was no difference within the control group but the actual REE measurements were significantly higher than the calculated BMR in the short-stature group. The same pattern was seen within the short-stature group when subjects were matched for height. There were no significant differences in RQ between the two groups.
\end{abstract}

Key words: Short-stature children, Resting energy expenditure, Indirect calorimetry, Energy requirement, Chronic malnutrition

IN CHILDREN, short stature has been used as an indicator of chronic malnutrition [1]. Among short-stature children, treatable diseases such as growth hormone deficiency and hypothyroidism account for approximately $5 \%$ of all causes [2-4]. In developed countries, short stature has not been investigated as a problem of malnutrition in children who have no underlying diseases, are not given dietary restrictions or do not have inappropriate dietary intake due to abuse or other reasons. However, it has been reported that many shortstature children who seek medical attention, regardless of cause, have psychosocial problems such as low self-esteem, social immaturity and aggression toward others [5].

We have been conducting a nutrition intervention in short-stature children with no underlying diseases,

Submitted Jul. 15, 2011; Accepted Dec. 20, 2011 as EJ11-0138

Released online in J-STAGE as advance publication Jan. 7, 2012

Correspondence to: Yukiko Nishimoto, Department of Nutrition, Osaka Medical Center and Research Institute for Maternal and Child Health, 840, Murodocho, Izumi-shi, Osaka 594-1101, Japan. E-mail: nisimoto@mch.pref.osaka.jp with an improvement in height observed in some cases. The first step of the nutrition intervention was a nutritional evaluation that included an assessment of food intake. In adults, the Harris-Benedict equation is used to estimate energy requirements [6]. However, it has been reported that in children, there is no correlation between energy expenditure (EE) obtained by indirect calorimetry and the Harris-Benedict values; therefore, Harris-Benedict values cannot be clinically used for children [7, 8].

The Dietary Reference Intakes for Japanese [9] (Dietary Reference Intakes) is commonly used to estimate energy requirements of Japanese children. These estimated energy requirements (EERs) are obtained by multiplying the basal metabolic rate (BMR) by the physical activity level and adding to it energy accumulated through growth. However, it is not clear what food intake standards should be used for people with abnormal physical size (e.g., short stature, obesity, etc.) and sick children, and actual measurement of EE is necessary to determine $\mathrm{EE}$ of children [10].

In the US, Han et al. reported on EE in children 
with constitutional delay of growth and malnutrition (CDGM) [11]. To the authors' knowledge, however, there has been no study of resting energy expenditure (REE) in Japanese children of short stature with no underlying disease (hereinafter referred to as short-stature children). Therefore, the BMR ( $\doteqdot \mathrm{REE}$ ), a component of energy requirements in short-stature children, was measured by indirect calorimetry and comparisons were made with age-matched children with normal stature. Furthermore, we compared actual REE not only with the calculated BMR that was calculated using the Dietary Reference Intakes in subjects within each group matched for age but for subjects within each group matched by height.

$<$ Definitions in the Dietary Reference Intakes for Japanese $>$

- BMR (basal metabolic rate )= basal metabolic standard $\times$ weight : calculated value

- EER (estimated energy requirement) $=$ BMR $\times$ physical activity level + energy accumulated through growth

- REE (resting energy expenditure): actually measured value is nearly equal to BMR

\section{Methods}

\section{Subjects}

Physical characteristics of the subjects are shown in Table 1.
The short-stature group consisted of 30 children (19 males, 11 females; age $6.1 \mathrm{y} \pm 1.7$ ) who sought medical attention at departments of gastrointestinal and endocrinology and were without underlying diseases, had normal results for the growth hormone secretion test within the previous two years, were prepubertal, had normal development and had a height -2 standard deviations (SD) or lower than normal for age. Children whose mid-parental height (MPH) [12] predicted from their parents' heights were -2 SD or lower were not eligible for the study. The control group was comprised of 13 normally developed, age- and obesity ratematched children (6 males, 7 females; age $6.3 \mathrm{y} \pm 2.2$ ) who volunteered to participate in the study and whose SDs for height were within \pm 1 SD. Each group was further divided into male and female subgroups.

\section{Evaluation of physical size}

Height, weight and arm circumference were measured to calculate the SD for height, obesity rate ([measured weight - standard weight]/standard weight $\times$ 100 ) and body surface area in both the short-stature group and control group. To calculate height SD and obesity rate, data from the National Growth Survey on Preschool Children (2000) conducted by the Ministry of Health, Labour and Welfare and data from the School Health Survey (2000) conducted by the Ministry of Education, Culture, Sports, Science and Technology were used and body surface area was calculated using

Table 1 Physical characteristic of subjects

\begin{tabular}{|c|c|c|c|c|c|c|c|c|}
\hline & $\mathrm{n}$ & $\begin{array}{l}\text { Age } \\
\text { (year) }\end{array}$ & $\begin{array}{l}\text { Height } \\
(\mathrm{cm})\end{array}$ & $\begin{array}{l}\text { Height score } \\
\text { (SD) }\end{array}$ & $\begin{array}{l}\text { Weight } \\
(\mathrm{kg})\end{array}$ & $\begin{array}{c}\text { Body- } \\
\text { surface area } \\
\left(\mathrm{m}^{2}\right)\end{array}$ & $\begin{array}{l}\text { Arm circum- } \\
\text { ference }(\mathrm{cm})\end{array}$ & $\begin{array}{c}\text { Obesity ratio } \\
(\%)\end{array}$ \\
\hline \multicolumn{9}{|l|}{ All subjects } \\
\hline Short stature & 30 & $6.1 \pm 1.7$ & $101.4 \pm 8.9$ & $-2.51 \pm 0.39$ & $15.0 \pm 3.1$ & $0.65 \pm 0.10$ & $15.7 \pm 1.2$ & $-1.33 \pm 9.69$ \\
\hline Control & 13 & $6.3 \pm 2.2$ & $113.7 \pm 14.3$ & $-0.07 \pm 0.71$ & $20.7 \pm 6.2$ & $0.80 \pm 0.17$ & $17.7 \pm 1.9$ & $-1.33 \pm 5.63$ \\
\hline$p$ values & & 0.7 & $0.001^{* *}$ & $<0.001^{\star \star}$ & $<0.001^{\star \star}$ & $<0.001^{\star \star}$ & $<0.001^{\star *}$ & 1.0 \\
\hline \multicolumn{9}{|l|}{ Males } \\
\hline Short stature & 19 & $6.4 \pm 1.9$ & $103.1 \pm 9.1$ & $-2.51 \pm 0.40$ & $15.3 \pm 3.7$ & $0.66 \pm 0.10$ & $15.5 \pm 1.4$ & $-2.47 \pm 10.18$ \\
\hline Control & 6 & $6.9 \pm 2.5$ & $116.9 \pm 14.8$ & $-0.22 \pm 0.86$ & $21.6 \pm 6.2$ & $0.84 \pm 0.18$ & $17.7 \pm 2.1$ & $-3.43 \pm 4.31$ \\
\hline$p$ values & & 0.6 & $0.010^{*}$ & $<0.001^{\star \star}$ & $0.005^{\star \star}$ & $0.006^{\star *}$ & $0.006^{\star *}$ & 0.8 \\
\hline \multicolumn{9}{|l|}{ Females } \\
\hline Short stature & 11 & $5.5 \pm 1.4$ & $98.4 \pm 8.1$ & $-2.51 \pm 0.37$ & $14.6 \pm 3.1$ & $0.65 \pm 0.10$ & $15.7 \pm 1.2$ & $-1.33 \pm 9.69$ \\
\hline Control & 7 & $5.7 \pm 2.1$ & $111.0 \pm 14.5$ & $-0.05 \pm 0.60$ & $19.9 \pm 6.5$ & $0.78 \pm 0.18$ & $17.7 \pm 2.0$ & $-0.48 \pm 6.29$ \\
\hline$p$ values & & 0.9 & $0.029^{\star}$ & $<0.001^{\star \star}$ & $0.021^{*}$ & $0.022^{*}$ & $0.034^{*}$ & 1.0 \\
\hline
\end{tabular}


DuBois's formula [13].

\section{Measurement of resting energy expenditure (REE)}

Using canopy indirect calorimetry (Deltatrac 90. 11. 26-036-2, Datex), fasting (no food for 3 hours or more) REE and RQ with the child in the supine position were measured. To maintain the arousal and resting state while in the supine position, the children in both groups watched animation DVDs during measurements.

\section{Compared items}

REE measurements and RQs were compared between the two groups. To adjust for body size, REE per weight $(\mathrm{REE} / \mathrm{kg})$ and REE per body surface area $\left(\mathrm{REE} / \mathrm{m}^{2}\right)$ were calculated and compared between the groups. Comparisons were made in each group between REE measurements and calculated BMRs that were acquired using BMR standards matched by age (Table 2) [14]. Additionally, in the short-stature group, such comparison was also made with calculated BMRs that were obtained using the BMR standards in children matched for height.

\section{Statistical test}

The $t$-test was used for comparison between the two groups, while the paired $t$-test was used for comparison between REE and BMR within in each group.

\section{Ethical considerations}

This study was conducted with the approval of the Osaka Medical Center and Research Institute for Maternal and Child Health and the research ethics committee of the School of Comprehensive Rehabilitation, Osaka Prefecture University, and with the written con-
Table 2 Standard basal metabolic rate

\begin{tabular}{ccc}
\hline Age & $\begin{array}{c}\text { Males } \\
\text { (kcal/kg/day) }\end{array}$ & $\begin{array}{c}\text { Females } \\
\text { (kcal/kg/day) }\end{array}$ \\
\hline $1 y$ & 59.9 & 59.9 \\
$2 y$ & 58.8 & 58.4 \\
$3 y$ & 57.2 & 56.5 \\
$4 y$ & 54.4 & 52.7 \\
$5 y$ & 51.0 & 48.4 \\
$6 y$ & 48.6 & 46.1 \\
$7 y$ & 45.6 & 42.9 \\
$8 y$ & 42.6 & 40.2 \\
$9 y$ & 39.7 & 37.6 \\
$10 y$ & 37.3 & 35.6 \\
$11 y$ & 35.3 & 33.3 \\
\hline
\end{tabular}

This table extracted from reference NO. 14.

sent of the subjects and their guardians.

\section{Results}

The subjects' physical characteristics are shown in Table 1. Weight, body surface area, and arm circumference as well as height were significantly lower in the short-stature group than in the control group ( $p=$ $0.0002, p=0.0004, p=0.0001)$. It was also the case with gender subgroups.

REE for the control group was $961 \pm 152 \mathrm{kcal} /$ day, which was significantly higher than that for the shortstature group $(867 \pm 121 \mathrm{kcal} /$ day $[p=0.035])$, but there was no significant difference in REE between the gender subgroups. There was neither a significant difference in RQ between the control group $(0.89 \pm 0.04)$ and the short-stature group $(0.88 \pm 0.05)(p=0.258)$ nor between the gender subgroups (Table 3 ).

REE adjusted for body size was significantly higher for the short-stature group than that for the control

Table 3 Comparison of energy expenditure and respiration quotient

\begin{tabular}{ccccccc}
\hline & \multicolumn{2}{c}{ All subjects } & \multicolumn{2}{c}{ Males } & \multicolumn{2}{c}{ Females } \\
\hline & $\begin{array}{c}\mathrm{REE} \\
(\mathrm{kcal} / \text { day })\end{array}$ & $\mathrm{RQ}$ & $\begin{array}{c}\mathrm{REE} \\
(\mathrm{kcal} / \text { day })\end{array}$ & $\mathrm{RQ}$ & $\begin{array}{c}\mathrm{REE} \\
(\mathrm{kcal} / \text { day })\end{array}$ & $\mathrm{RQ}$ \\
\hline Short stature & & & & & & \\
mean $\pm \mathrm{SD}$ & $867 \pm 121$ & $0.88 \pm 0.05$ & $889 \pm 132$ & $0.88 \pm 0.05$ & $827 \pm 91$ & $0.88 \pm 0.06$ \\
median & 860 & 0.88 & 900 & 0.88 & 835 & 0.89 \\
min/max & $610 / 1270$ & $0.76 / 0.96$ & $610 / 1270$ & $0.76 / 0.96$ & $700 / 980$ & $0.76 / 0.95$ \\
Control & & & & & \\
mean $\pm \mathrm{SD}$ & $961 \pm 152$ & $0.89 \pm 0.04$ & $1017 \pm 160$ & $0.89 \pm 0.05$ & $913 \pm 137$ & $0.89 \pm 0.03$ \\
median & 950 & 0.89 & 1015 & 0.87 & 880 & 0.89 \\
min/max & $760 / 1200$ & $0.84 / 0.96$ & $780 / 1200$ & $0.84 / 0.96$ & $760 / 1170$ & $0.86 / 0.95$ \\
$p$ values & $0.035^{*}$ & 0.258 & 0.062 & 0.551 & 0.127 & 0.322 \\
\hline REE, resting energy expenditure; RQ, respiration quotient & REE: Measurements ${ }^{*} p<0.05$
\end{tabular}


Table 4 Comparison of REE per body weight and the body-surface area

\begin{tabular}{|c|c|c|c|}
\hline & $\mathrm{n}$ & $\begin{array}{l}\text { REE/Weight } \\
\text { (kcal/kg/day) }\end{array}$ & $\begin{array}{l}\text { REE/Body-surface area } \\
\text { (kcal/m²/day) }\end{array}$ \\
\hline \multicolumn{4}{|l|}{ All subjects } \\
\hline Short stature & 30 & $58.8 \pm 8.4$ & $1350.5 \pm 157.6$ \\
\hline Control & 13 & $48.3 \pm 7.3$ & $1209.9 \pm 103.9$ \\
\hline$p$ values & & $<0.001^{\star \star}$ & $0.005^{\star *}$ \\
\hline \multicolumn{4}{|l|}{ Males } \\
\hline Short stature & 19 & $59.5 \pm 8.6$ & $1357.7 \pm 142.2$ \\
\hline Control & 6 & $47.8 \pm 8.3$ & $1231.5 \pm 115.4$ \\
\hline$p$ values & & $0.014^{\star}$ & 0.061 \\
\hline \multicolumn{4}{|l|}{ Females } \\
\hline Short stature & 11 & $57.6 \pm 8.2$ & $1321.1 \pm 261.0$ \\
\hline Control & 7 & $47.8 \pm 7.1$ & $1191.5 \pm 98.2$ \\
\hline$p$ values & & $0.019^{*}$ & 0.077 \\
\hline
\end{tabular}

REE, resting energy expenditure REE: Measurements Data presented as means \pm SD ${ }^{*} p<0.05{ }^{* *} p<0.01$

Table 5 Comparison of REE measurements and BMR calculated from the dietary reference intakes (kcal/day)

\begin{tabular}{lccc}
\hline & All subjects & Males & Females \\
\hline Short stature & & & \\
REE & $867 \pm 121$ & $889 \pm 132$ & $827 \pm 91$ \\
Age matched BMR & $726 \pm 53$ & $738 \pm 58$ & $705 \pm 38$ \\
$p$ values & $<0.001^{\star *}$ & $<0.001^{\star *}$ & $0.005^{\star \star}$ \\
REE & $867 \pm 121$ & $889 \pm 132$ & $827 \pm 91$ \\
Height matched BMR & $814 \pm 115$ & $815 \pm 132$ & $791 \pm 84$ \\
$p$ values & $<0.001^{\star \star}$ & $<0.001^{\star \star}$ & 0.159 \\
Control & & & \\
REE & $961 \pm 152$ & $1017 \pm 160$ & $913 \pm 137$ \\
Age matched BMR & $949 \pm 162$ & $983 \pm 178$ & $920 \pm 154$ \\
$p$ values & 0.467 & 0.189 & 0.726 \\
\hline
\end{tabular}

REE, resting energy expenditure; BMR, basal metabolic rate ${ }^{\star *} p<0.01$

REE: Measurements, BMR: calculated value Data presented as means $\pm \mathrm{SD}$

group; REE $/ \mathrm{kg}$ was $58.8 \pm 8.4 \mathrm{kcal} / \mathrm{kg}$ for the shortstature group and $48.3 \pm 7.3 \mathrm{kcal} / \mathrm{kg}$ for the control group $(p<0.001)$. It was also the case with comparisons between the gender subgroups ( $p=0.04$ for the male subgroup, $p=0.019$ for the female subgroup) (Table 4). Although $\mathrm{REE} / \mathrm{m}^{2}$ was not different between the gender subgroups, it was significantly higher in the shortstature group than in the control group: $1350.5 \pm 157.6$ $\mathrm{kcal} / \mathrm{m}^{2}$ for former group and $1209.9 \pm 103.9 \mathrm{kcal} / \mathrm{m}^{2}$ for the latter group ( $p=0.0003, p=0.0053)$ (Table 4). A comparison of actual REEs with BMRs calculated from the Dietary Reference Intakes (Table 2) in each group is shown in Table 5. Whereas there was no dif- ference between the actual REE and age-matched calculated BMR in the control group ( $p=0.467)$, the actual REE was higher than the age-matched calculated BMR in the short-stature group $(867 \pm 121$ vs. $726 \pm 53 \mathrm{kcal} /$ day, $p<0.001$ ).

Also in gender subgroups, the actual REE was significantly higher than the age-matched calculated BMR: $889 \pm 132$ vs. $738 \pm 58 \mathrm{kcal} /$ day for males, $p<0.001$; $827 \pm 91$ vs. $705 \pm 38 \mathrm{kcal} /$ day for females, $p=0.005$ ). In the short-stature group, the actual REE was significantly higher than height-matched calculated BMR on the whole as well as in the male subgroup $(814 \pm 115$ $\mathrm{kcal} /$ day for the whole, $p<0.001 ; 815 \pm 132 \mathrm{kcal} /$ day for 
males, $p<0.001$ ), although there was no such significant difference in the female subgroup.

\section{Discussion}

Measuring the BMR of children is not easy since it is difficult to keep them rested and aroused at the same time for a certain period of time or to maintain their fast for many hours [15]. In this study, to avoid the effects of heat production by dietary intake, fasting (created by 2 conditions: no breakfast and no food for 3 hours) REE and RQ with the child in the supine position were measured and compared among 7 children (4 males, 3 females, age $6.4 \pm 2.4$, obesity rate -2.1 $\pm 4.4 \%$ ) who were randomly extracted from the control group. There was no significant difference in the REE between the two fasting conditions $(1053 \pm 161$ $\mathrm{kcal}$ for no breakfast and $1049 \pm 151 \mathrm{kcal}$ for no food in the previous 3 hours, $p=0.83$ ) and in the resting RQ between the two fasting conditions $(0.88 \pm 0.07$ for no breakfast and $0.92 \pm 0.10$ for no food in the previous 3 hours, $p=0.10$ ). Therefore, the measurements taken 3 hours after the last meal were used as REEs.

In this study, REE measurements were significantly higher for the control group than for the short-stature group, possibly because weight and body surface area were higher in the control group. However, in many studies, BMR is adjusted for weight $(\mathrm{BMR} / \mathrm{kg})$ according to gender and age category [9]. In this study, $\mathrm{REE} / \mathrm{kg}$, which was the REE adjusted for weight, was significantly higher for the short-stature group than for the control group. REE $/ \mathrm{m}^{2}$, which was the REE adjusted for body surface area, was also significantly higher for the short-stature group as a whole whereas there were no significant differences between the gender subgroups.

There was no difference in the obesity rate between the two groups and the arm circumference was lower in the short-stature group; therefore, muscle mass was not particularly higher for the short-stature group [16].

For the control group, the actual REE was almost identical to the calculated BMR. However, in the short-stature group, the actual REE was significantly higher than the age-matched calculated BMR and also than the height-matched calculated BMR, although by a narrower margin as compared to age-matched calculated BMR. These results were in accordance with the report by Han et al. on EE in CDGM [11]. It was therefore suggested that energy metabolism in the short-stat- ure child is augmented by some unknown factors.

Generally in Japanese people, basal metabolic standards adjusted for weight for each gender and age category are used to estimate energy requirements, and BMR is obtained by multiplying the basal metabolic standard by weight [9]. It was suggested that underestimation might occur if the basal metabolic standards of the Dietary Reference Intakes matched by age were used as they were to calculate the BMR for short-stature children.

With the Dietary Reference Intakes, total energy expenditure (TEE) is also calculated by multiplying the BMR by the physical activity level [9]. The physical activity level needs to be determined in consideration of heat generated by dietary intake and the daily activity energy, which vary greatly among individuals. Han et al. reported a very high TEE in CDGM as assessed using doubly labeled water but it is doubtful that such a high TEE occurs commonly in all CDGM. These investigators associated this high TEE with a possible genetic mutation [11]. In line with the report by Han et al., our short-stature children had an actual REE that tended to be closer to the calculated BMR acquired by matching their height to ages younger than actual ages. This may be simply because their metabolic state is equivalent to that of children younger than the actual ages of the short-stature group.

Furthermore, in children, the EER is the total of EE and energy accumulated with growth, that is, an increase in tissue [9]. In other words, healthy growth of children cannot be expected if they do not secure an energy intake that covers their EE plus energy accumulated with growth. Our results showed that the body-size-adjusted REE of short-stature children with no underlying diseases was higher than that of standard-stature children and that the absolute REE measurements were higher than BMR calculated from the Dietary Reference Intakes. It is possible that the EER, as well as BMR, of short-stature children is also higher and that such children do not ingest a sufficient amount of food to meet these needs.

There was little difference in the RQ between the short-stature group (0.88) and the control group (0.89). The RQ is the ratio of the volume of $\mathrm{CO}_{2}$ produced by the oxidization of nutrients in the body to $\mathrm{O}_{2}$ consumed and is normally between 1 and 0.8 , and varies according to diet and physical activity level [17]. Because the RQ level was similar between the two groups, it was suggested that the short-stature children did not suffer 
from chronic malnutrition by which fat is rapidly burned due to extremely insufficient dietary intake or excessive physical activity but were instead in a steady state. However, determining whether short stature is caused by a long-term mild insufficiency in dietary intake due to an inappropriately high BMR for the patient's age, whether short stature elevates metabolism, or whether there are external factors that enhance metabolism are issues to be investigated in the future.

Han et al. reported that there was no difference in nutrition markers or in body composition between a non-CDGM group that took liquid nutrition supplements in addition to a regular diet and a CDGM group [18]. Our survey of dietary intake in short-stature children revealed that they ingested a smaller amount of especially carbohydrate than normal children (unpublished data), indicating the necessity of studying whether supplementation of energetic substrate (carbohydrate), which is lacking in short-stature children, should improve their body size. Furthermore, it is necessary in the future to examine the TEE in these children using the double-labeled water method [19-21], which is the gold standard for this purpose in order to study energy metabolism taking the genetic back- ground into consideration.

\section{Conclusion}

The REE, which was nearly equivalent to BMR, and the RQ of short-stature children were measured by indirect calorimetry and compared with corresponding values obtained in standard-stature children. Bodysize-adjusted REE was also compared between the two groups. Furthermore, REE measurements were compared with BMRs calculated from the Dietary Reference Intakes. The body-size-adjusted REE measurements in short-stature children were significantly higher than those in standard-stature children. While the REE measurements were almost the same as the BMR calculated from the Dietary Reference Intakes in standard-stature children, those of short-stature children were significantly higher than calculated BMRs from the BMR standards matched by age. It was thus suggested that underestimation might occur if the Dietary Reference Intakes were used to calculate BMRs in short-stature children. Further studies are needed regarding high REE in short-stature children.

\section{References}

1. Waterlow JC (1973) Note on the assessment and classification of proteinenergy malunutrition in children. Lancet 2:87-89.

2. Floor KG, Wilma O, Sabine M, Paula VD, Stef VB, Friedo WD, Arnoldus GK, Henriette AM, Jan MW (2008) The diagnostic work up of growth failure in secondary health care; An evaluation of consensus guidelines. Available at: http: //www. biomedcentral. com/1471-2431/8/21

3. Gudrun R, Werner FB, Elena PS, Brenda JC, Ralph R, Charmian AQ, Judith LR, Beate N (2007) Genotypes and phenotypes in children with short stature: clinical indicators of SHOX haploinsufficiency. J Med Genet 44: 306-313.

4. Tanaka T (2005) Recent progress in the differentiation and treatment of short stature. Jpn J Pediatr 58:319-328 (In Japanese).

5. Tachibana K (2007) Psychosocial problems in and treatment of short-stature children. J Pediatr Pract 10:17311737 (In Japanese).

6. Harris JA, Benedict FG (1919) A biometric studies of basal metabolism in man. Washington, DC: Carnegie Institute, Publ 279, p266.
7. Coss-Bu JA, Jefferson LS, Walding D, David Y, Smith EO, Klish WJ (1998) Resting energy expenditure in children in a pediatric intensive care unit: comparison of Harris-Benedict and Talbot predictions with indirect calorimetry values. Am J Clin Nutr 67:74-80.

8. Amagai T, Kaneko M, Ohkawa H (1999) Formula to predict energy expenditure in infants-Using Indirect Calorimetry -. Jpn J Surg Metab Nutr 33:187-193 (In Japanese).

9. Ministry of Health, Labour and Welfare (ed) (2009) 2010 Dietary Reference Intakes for Japanese. Daiichi Shuppan Publishing Co. Ltd: Tokyo, p.43-60 (In Japanese).

10. Shakur YA, Richards H, Pencharz PB (2008) Is it necessary to measure resting energy expenditure in clinical practice in children? J Pediatr 152:437-439.

11. Han JC, Balagopal P, Sweeten S, Darmaun D, Mauras N (2006) Evidence for hypermetabolism in boys with constitution dalay of growth and maturation. J Clin Endocrinol Metab 91:2081-2086.

12. Ogarta T, Tanaka T, Kagami M (2007) Target height and target ranget for Japanese children. Clin Pediatr Endocrinol 16:85-87. 
13. DuBois D, DuBois EF (1916) Clinical calorimetry. X A formula to estimate the approximate surface area if height and weight be known. Arch Intern Med 17: 863871.

14. Nakayama T, Iriki M (eds) (1987) Handbook of Physiological Sciences Vol.22 Physiology of Energy Exchange and Thermoregulation. Igaku-Shoin Ltd, Tokyo, p.60-62 (In Japanese).

15. Bines JE, Truby HD (2004) Measurement of resting energy expenditure in infants. $J$ Pediatr Child Health 40:380-383.

16. Murata M (2009) The definition, diagnosis, and evaluation of lean and malnourished person. Jpn J Pediatr Med 41:1259-1263 (In Japanese).

17. Bursztein S, Elwyn DH, Askanazi J, Kinney JM (eds) (1989) Energy Metabolism, Indirect Calorimetry, and
Nutrition. William \& Wilkins: USA, p.17-21.

18. Han JC, Damaso L, Welsh S, Balagopal P, Hossain J, Mauras N (2011) Effects of growth hormone and nutritional therapy in boysn with constitutional growth delay: A randomized controlled trial. J Pediatr 158:427-432.

19. Lifson N, Little WS, Levitt DG, Henderson RM (1975) $\mathrm{D}_{2}{ }^{18} \mathrm{O}$ method for $\mathrm{CO}_{2}$ output in small mammals and economic feasibility in man. J Appl Physiol 39:657664.

20. Schoeller DA, Santen EV (1982) Measurement of expenditure in humans by doubly labeled water. $J$ Appl Physiol 53:955-959.

21. Schoeller DA, Webb P (1984) Five-day comparison of the doublty labeled water method with respiratory gas exchange. Am J Clin Nutr 40:153-158. 